\title{
El sinuoso camino hacia un Estado de políticas públicas
}

Víctor S. Peña ${ }^{1}$

\begin{abstract}
"No importa qué tan sofisticadas sean las propuestas analíticas
o qué tan precisos sean los métodos empleados, de cualquier modo, no existe una respuesta exacta a la pregunta sobre la mejor forma de garantizar un gobierno digno de la sociedad a la que sirve."
\end{abstract}

Mauricio Merino (2013, p. 9)

\section{Introducción}

Como la llama que rápidamente se propaga sobre vegetación seca, el término "políticas públicas" ha venido haciéndose presente en el discurso, la planeación y la ejecución de mucho de lo que observamos como gubernamental. La metáfora no es gratuita: aplica, por supuesto, a la velocidad con la que el término se ha ganado un espacio propio y, al mismo tiempo, con las consecuencias esperadas. Las visiones se polarizan: hay quienes lo perciben como un nuevo enfoque (disciplina, ciencia) que

1 Doctor en Política Pública y Maestro en Administración Pública y Políticas Públicas por el Tecnológico de Monterrey. Estancias académicas en la Universidad San Martín de Porres (Perú), la Universidad de Santiago de Chile, el Consejo de Participación Ciudadana y Control Social (Ecuador) y el Instituto de Investigación Urbana y Territorial (España). Miembro del Sistema de Investigadores de México. 
resulta benéfico para abordar y solucionar conflictos, el fuego que viene a purificar las estructuras y terminar con las inercias; mientras que otros enfatizan su origen y subsistencia en un sistema diferente al nuestro -al latinoamericano-, por lo que ven una llama devastadora.

Una primera e inevitable cuestión es: ¿qué se entiende por "políticas públicas"? Autores contemporáneos ofrecen ya una propuesta bastante acabada de ello. Sin embargo, tanto en la literatura como en la discusión alrededor del tema subsisten diferentes aproximaciones que bien pudieran considerarse de acuerdo con la realidad o situación enfrentada.

A reserva de lo que el propio texto expondrá, provisionalmente entendamos por "política pública" -como lo propone Stella Z. Theodoulou (1995)-, un curso de acción con metas y objetivos, que no está limitado a una propuesta legislativa, que idealmente involucra distintas áreas y niveles de lo gubernamental, que es un proceso y, finalmente, que existe una diferencia entre lo que se pretende hacer y lo que se termina haciendo. Así visto, no parece enfrentarse con lo que hasta ahora conocemos como administración pública o acción gubernamental. Hay, sin embargo, un trasfondo que vale la pena sacar a flote para entender que el tránsito hacia un Estado que empleé políticas públicas no es una acción automática.

Entre lo menos evidente pero más significativo; es decir, la agenda ideológica, las políticas públicas surgen como una propuesta con agenda y valores liberales. Las razones de las acciones del Gobierno, que atienden a un fin más acotado y están diseñadas a partir de un criterio de escases o eficiencia (según se le quiera ver), es otro aspecto diferente. Entre tanto, la posición del gobernado en ocasiones puede ser como cliente, como beneficiario o como corresponsable de la solución, teniendo en cuenta que la lista puede continuar.

En breve espacio, este capítulo presenta un desarrollo esquemático de la evolución del Estado siguiendo una misma línea de análisis: la posición de la administración pública. De esta manera, se considera, puede ubicarse con mayor facilidad el camino conceptual y temporal recorrido en la búsqueda de soluciones a las inquietudes de los gobernados; del origen y hasta la actualidad, donde las "políticas públicas" se constituyen como paradigma dominante.

\section{El Estado como idea de donde todo parte}

Aun cuando se puede estar tan familiarizado con la voz Estado, tanto como para considerar ha existido siempre, debe tenerse en la cuenta que no se contó, en la antigüedad, con una figura exactamente equivalente; se empleaba la polis como forma 
política a partir de la organización de la gens ${ }^{2}$ o la civitas, habiendo entre uno y otro la importante distinción en que en la primera había un grupo humano identificable en cuya dinámica lo político florecía cara a cara y, en la segunda, se experimentaba ya con mecanismos para construir decisiones mucho más complejas y mediante intermediarios (Sartori, 1992). Esto, por supuesto, si optamos por el conocimiento occidental; otras referencias nos faltarían si apeláramos a la organización de los asentamientos originarios de lo que hoy conocemos como América Latina.

La aparición del concepto se encuentra a la par del pensamiento moderno. Con Maquiavelo se establece su uso, como una reflexión sobre un poder desprendido de la sociedad y un cuestionamiento sobre cómo alcanzarlo y, una vez conseguido, cómo conservarlo (Maquiavelo, 1975). Es, entonces, el Estado moderno una categoría histórica que difiere de las autarquías medievales y los imperios orientales (Guerrero, El Estado en la Era de la Modernización, 1992); es decir, la palabra Estado corresponde a la fase actual de la organización política.

Apresurando la historia, tras el derrumbamiento de la organización medieval el Estado se consolidó como una idea proyectada a la realidad a través de la cual se justificó el ejercicio del poder y la distribución de actividades de manera tal que quedara en unos pocos la potestad de tomar las decisiones que incidirían en la vida de la mayoría (Zarka, 2001; Pokrovski, 1966; Wright Mills, 1964). Esta distribución de actividades llevó a la especialización, reforzándose el paradigma que justificaba la concentración del poder en una clase político-burocrática.

Lo que pudiera denominarse como el 'Estado burocrático', con una configuración más racional, aparece hacia finales del siglo XIX. Max Weber (2002) señala que, prácticamente en todas las organizaciones políticas, el señor organiza los medios materiales de la administración por medio de personas que dependan personalmente de él. Como culminación del proceso, el Estado controla todos los medios de la organización política reunidos en un solo gobernante. De hecho, es en el Estado moderno en el que se hace una clara separación entre el personal administrativo y los medios materiales de la organización administrativa.

El desarrollo del capitalismo y los procesos de racionalización del Estado son propios de la sociedad moderna. Weber (2002) señala que la organización del Estado, por medio de una burocracia racional, basado en la justicia y administración, es necesaria para la existencia de la empresa capitalista moderna ${ }^{3}$.

\footnotetext{
$2 \quad$ Es en el libro de Friedrich Engels (1983) en el cual se desarrolla, desde el materialismo histórico, que la génesis del Estado ateniense y la gens romana coincidirían con la aparición de la propiedad privada y la distinción de clases sociales.

3 "Pero también históricamente, el "progreso" hacia lo burocrático, hacia el Estado que juzga y administra asimismo conforme a un derecho estatuido y a reglamentos concebidos racionalmente, está en la conexión más
} 
Es así, por medio de formas racionales de la burocracia del Estado, que preexiste el capitalismo moderno; de lo contrario quedaría a la deriva de decisiones arbitrarias, puesto que las empresas modernas son sensibles a la falta de servicios e infraestructuras para reclamar por sí sus derechos. La racionalización de estas dos organizaciones, así como la empresa capitalista y la burocrática, se caracterizan de las anteriores por ser más eficientes, puesto que se organizan basados en cálculo. Esta racionalización presupone un mismo objetivo de acción en todos sus participantes, lo que simplifica y da prontitud a la coordinación de las interacciones de ellos (Zarka, 2001; Ferraro, 2009).

Esta racionalización implica que las actuaciones de los miembros de las organizaciones, por decir burocráticas, van encaminadas a un fin. El comportamiento del miembro de la organización pública o privada va encaminado a cumplir los fines de esta organización, mientras que estos no se ponen en tela de juicio (Ferraro, 2009). La concepción de una organización con un fin o destino combina el esfuerzo de algunos pocos para lograr el bien público temporal y es justo allí donde se desarrolló el Estado actual.

Es -con apelación a la racionalización del Estado en su forma burocrática para alcanzar los fines- el escenario en el que se plantean la mayoría de la conceptualización de esta organización política. Max Weber (2002) afirma que es una comunidad humana, dentro de los límites de un territorio establecido, que reclama el monopolio de la legítima violencia física. Es en la reflexión de este concepto obligado para la teoría política donde se comprende a esta figura no solo por sus fines, ya que no existe alguna asociación política que en sus acciones estén destinadas a cumplir objetivos, sino por los medios para alcanzarlos: la coacción física. Así mismo, se caracteriza como se conoce al Estado centralista: un ente con orden jurídico e institucional por el que se orienta la actividad administrativa para cumplir con determinados fines (regidos por preceptos estatuidos). Lo anterior se simplifica con la definición de (Porrúa Pérez, 1976):

“[...] Una sociedad humana, asentada de manera permanente en el territorio que le corresponde, sujeta a un poder soberano que crea, define y aplica un orden jurídico que estructura la sociedad estatal para obtener el bien público temporal de sus componentes". Lo que significa, para la teoría del Estado, la conservación y justificación del Estado administrativo, es en base a las funciones y atribuciones del mismo (p. 118).

\footnotetext{
íntima con el desarrollo capitalista moderno. La empresa capitalista moderna descansa internamente ante todo en el cálculo. Necesita para su existencia una justicia y una administración cuyo funcionamiento puede calcularse racionalmente, por lo menos en principio, por normas fijas generales con tanta exactitud cómo puede calcularse el rendimiento probable de una máquina" (Weber, 2002, p. 1062).
} 
Hermann Heller (2010) menciona que el Estado vive de su justificación.Todo poder existencial tiene que aspirar a ser poder jurídico; pero no significa actuar en sentido técnico-jurídico, sino valer como autoridad legítima que obliga moralmente a la voluntad. Por eso, al no separar lo jurídico con lo antijurídico, no es posible hablar de justificación, pues es al criterio jurídico al que le incumbe regular rectamente la vida social. Es decir, el Estado está justificado en cuanto representa la organización necesaria para asegurar el derecho de una determinada etapa de su evolución. Es la protección a la carga axiológica de las normas jurídicas la justificación del actuar del Estado, cuya validez ideal es inmanente a la validez del actuar estatal como medio para alcanzar determinado fin. Es la manifestación de la actividad del Estado la que justifica su existencia: esta organización jurídica solo existe en sus resultados.

La actividad del Estado administrativo se refiere a todo acto material o simbólico que realiza en virtud de las atribuciones que las normas jurídicas le otorgan. Es otro término que va afinando las características que ha adoptado la organización a partir de especialización. La actividad del Estado se ostenta por medio de la actuación de sus gobernantes que actúan formando parte de estructuras de este mismo, lo que Porrúa Pérez (1976) llama "órganos". Estos, en su conjunto, integran el gobierno y la administración del Estado.

Por otra parte, otorgar atribuciones recae en la necesidad de crear los medios adecuados para alcanzar los fines gubernamentales. Sin embargo, estas atribuciones han variado en espacio y tiempo por la concepción histórica del Estado. En la primera generación de facultades, influida por el liberalismo que considera la actividad privada y la mano invisible del mercado suficientes para satisfacer las necesidades individuales y colectivas dentro de la sociedad, el Estado se vio reducido en fines y, por lo tanto, en su competencia. En esta etapa histórica, el Estado tuvo facultades de policía que lo obligaban a abstenerse de actuar fuera de los límites necesarios para mantener el orden, motivo por el cual se le concibe en esta etapa, dentro de la teoría del Estado, como Estado gendarme.

En contraparte, durante la crisis del Estado liberal por no respetar el principio de igualdad y no ser capaz de satisfacer las necesidades de la colectividad, se desarrolla una tendencia intervencionista que impone restricciones a la actividad privada para equilibrarla con el interés general (Fraga, 2009). Esto es justificar su actuación con el fin de estructurar la sociedad con ideales de justicia que no logró el capitalismo en el sistema liberal. Gabino Fraga observa que es en este contexto sociopolítico donde se conservan las actuales atribuciones del Estado: “a) atribuciones de mando, de policía y de coacción que comprenden los actos necesarios para el mantenimiento y protección del Estado y de la seguridad, la salubridad y el orden público; b) atribuciones para crear servicios públicos; c) atribuciones para intervenir mediante gestión directa en la vida económica, cultural y social del país" (Fraga, 2009, p. 15). 
Todo Estado, de manera independiente de su justificación ideológica, tiene que realizar funciones. Es precisamente en el sentido de alcanzar el bien público cuando el Estado realiza actividades. Es por medio de estas actividades que el Estado busca cumplir sus fines que lo originan y lo justifican (Porrúa Pérez, 1976). Para realizar sus fines, la actividad del Estado corresponde a su estructura orgánica inmediata. Las funciones constituyen la forma en que el Estado busca el ejercicio de las facultades otorgadas en las leyes administrativas; ergo, no se diversifican entre sí por el hecho de que cada una de ellas tenga atribución diferente, pues pueden servir para realizar una misma facultad (Fraga, 2009).

La división de poderes, como teoría política necesaria para combatir el absolutismo y establecer un gobierno sumiso al derecho, se ha convertido en un principio básico en la organización de las funciones de los Estados modernos (Wright Mills, 1964; Fraga, 2009). Lo que implica la separación de los órganos del Estado en tres grupos diversos e independientes, y cada uno de ellos constituido en forma que los diversos elementos que lo integran guarden entre sí la unidad que les da el carácter de Poder (op. cit., 2009). Esta división impone a la teoría del Estado a distribuir las funciones diferentes entre cada uno de los órganos facultados. Es así la manera clásica de clasificar las funciones del Estado:

"1. En toda organización estatal tiene que existir una actividad encaminada a formular las normas generales que deben, en primer término, estructurar al Estado y, en segundo término, reglamentar las relaciones entre el Estado y los ciudadanos y las relaciones de los ciudadanos entre sí; 2. Todo Estado debe tener una función encaminada a tutelar el ordenamiento jurídico definiendo la norma precisa que aplicar en los casos particulares; y, 3. La tercera función esencial del Estado es actuar promoviendo la satisfacción de las necesidades de los ciudadanos y fomentando el bienestar y el progreso de la colectividad" (Porrúa Pérez, 1976, p. 392).

Sin embargo, se debe tener en cuenta que no existe una distinción tajante entre las funciones que realiza el Estado. De manera que la legislación positiva no ha mantenido esta abrupta distinción ya que las necesidades empíricas han vuelto flexible la atribución de un mismo poder de funciones de naturaleza diferente. Por ese motivo, el derecho administrativo ha visto la necesidad de clasificar las funciones del Estado en dos categorías: a) desde el punto de vista del órgano que las realiza, con adopción de un criterio formal, subjetivo u orgánico, que prescinde la naturaleza intrínseca de la actividad; es decir, las funciones son legislativas, judiciales o administrativas atribuidas a los órganos legislativos, judiciales y administrativos; b) desde el punto de vista de la naturaleza intrínseca de la función; es decir, partiendo de un objetivo 
material que prescinde del órgano al cual están atribuidas (Fraga, 2009). En otras palabras, en la actualidad no existe diferenciación entre la división de poderes y la división de funciones.

\section{Administración y política}

La administración y la política son elementos inherentes del Estado, pues están presentes en el apretado desarrollo compartido en la sección anterior. Su conocimiento no es sencillo: en las preguntas de cómo, por qué y para qué se organiza el Estado se congregan una variedad en las ciencias sociales y políticas que construyen las respuestas desde su lente teórico.

La administración del Estado es sinónimo de la administración pública por cuanto el Estado personifica lo público (Guerrero, 2000). No fue hasta el siglo XIX cuando los estudiosos del Estado ofrecieron una teoría específica de la administración pública que hasta el momento había sido materia de la teoría política (Zarka, 2001). Esto como la culminación de un desarrollo que comenzaría un siglo antes, cuando se empezó a estudiar al Estado y su administración, pues hasta entonces la etapa estatal vigente correspondía al absolutismo y a un mundo político habitado por sus súbditos. En ese entonces la administración respondía a la voz de policía, cuya configuración alcanzó el nivel de primera disciplina de la administración en tanto que lo público estaba ausente en materia. Sus rasgos prominentes son la separación entre la administración y justicia, la asunción de deberes sociales con carácter público, la emergencia de interioridad como motor de un proyecto de desarrollo nacional y el establecimiento de carreras administrativas de servicio público (Guerrero, 2000, p. 32). El eje de convergencia de estos rasgos es lo administrativo, suceso caracterizado por la complejidad gubernamental para obtener identidad y así diferenciarse de lo económico, financiero y social.

No obstante, en este tránsito de la consolidación de su primera modalidad teórica como policía, la administración pública correspondía a un tipo de modelo de Estado concreto: el absolutista. Fue en la Revolución Francesa cuando el súbdito se convirtió en ciudadano y con ello hizo de la administración una forma de servirse a sí mismo como pueblo corresponsal de cumplir su soberanía. Desde entonces lo público quedó personificado en una organización estatal sometida a amparar los derechos fundamentales del hombre, en un Estado supeditado a la voluntad general del pueblo (Guerrero, 2000). Por ello, el vocablo policía quedó rezagado junto con la esencia del Estado absolutista, y en su lugar imperó la palabra administración, que la fenoménica social del momento impuso con énfasis el adjetivo de pública. 
En esta transición es visible la influencia de la carga teórica de la ciencia política, así como la aparición de nuevos rasgos cuyo origen -dice Omar Guerrero- "es lo público concebido como una gesta de la civilidad bajo la doble noción de res publica y de ciudadanía" (2000, p. 34).

La característica principal de la administración del Estado actual es lo público. Este concepto que Parsons define como "aquella actividad humana que se cree que requiere la regulación o intervención gubernamental o social, o por lo menos la adopción de medidas comunes" (Parsons, 2007, p. 37), es una emancipación del concepto pueblo: populus-puplicus-publicus-público. De modo que la administración pública se refiere a administrar la cosa del pueblo. Es en este sentido que agrega Omar Guerrero: "público es una categoría comprensiva que es incumbente a la totalidad del pueblo políticamente organizado, donde impera el interés colectivo y de la vida comunitaria" (2000, p. 39). Fue hasta la Revolución Francesa que existó la distinción entre la vida pública y vida privada, lo que conllevó a la reconfiguración del concepto público que busca la mediación y conciliación entre el hombre como átomo de la sociedad y a la sociedad estructurada por hombres. Es, en este nuevo público, donde florece la administración pública moderna y de donde emana la participación social y la actividad cívica (Guerrero, 2000).

Es en ese sentido que la administración pública presenta doble implicación: en primer lugar, la existencia de las relaciones administrativas dentro y fuera del Estado, y las relaciones de los individuos frente al Gobierno. Por otro lado, considerar al hombre como ciudadano que requiere objetos para satisfacer sus necesidades de progreso y de existencia. Es decir, la administración de lo público enfrenta doble situación: cómo se organiza el Estado por medio del administrador, y además tratar al hombre en su calidad de ciudadano y administrado.

Es en esta época cuando se consolidó el Estado liberal. Recae en la obligación de organizar los aparatos burocráticos sobre la base en criterios racionales capaces de contrarrestar el poder absoluto del Estado policial, que limitaba la capacidad de la libertad creadora del ser humano (Quiroga Lanvié, 1987). El papel del Estado debía ser garantista; es decir, era el encargado de asegurar el ejercicio de las libertades individuales. En palabras de Omar Guerrero, "el Estado revolucionario es un Estado de Derecho, se basa en la ley que somete por igual a gobernantes y gobernados. Las leyes son un elemento clave para la identificación y la definición de la administración pública moderna, en contraste con la antigua policía" (2000, p. 48). Esta transición se caracteriza por la convivencia armónica de la administración del Estado con la Constitución: el derecho como base ideal de la voluntad de ciudadanos iguales ante la ley, en el marco de la normatividad positiva capaz de organizar la convivencia social. En ese sentido, organizar al Estado desde la constitución no solo significaba arrebatar la soberanía y el poder al antiguo orden, sino establecer los criterios a partir de los 
cuales fuera posible mantener a una sociedad organizada y garantizar las libertades sociales que recién se habían ganado. La naturaleza de la administración pública se convertiría en el medio privilegiado para implantar el nuevo régimen a partir del Estado de derecho (Merino, 2013).

Es en esta nueva concepción de la administración pública a donde se trasladó la racionalidad administrativa basada en las obligaciones que se desprendían de los estatutos fijados en el derecho. El producto es una burocracia neutral yprofesionalmente preparada para cumplir sus obligaciones de manera imparcial. Max Weber (2002) señala la operación de esta burocracia moderna: se basa en principios jurisdiccionales establecidos por normas y leyes administrativas; organizada de manera jerárquica, en la que los funcionarios superiores puedan establecer obligaciones y mandatos para controlar a los funcionarios de abajo; su base se funda en su capacidad de archivo de documentos escritos que se conservan de forma original o de proyecto; esto es, administrar el cargo de manera especializada con una preparación cabal y experta.

El liberalismo se impuso a mediados del siglo xIX, tanto en la teoría como en la práctica de la realidad inglesa. La situación de la clase obrera empeoró bastante por la desaparición de las medidas protectoras. Por esto, para una buena parte de la clase trabajadora británica el liberalismo económico inició la etapa más sórdida de su historia. Fue una época de crisis para el liberalismo que desembocó en los años treinta donde se establecía que el Estado debía asumir un papel mucho más activo en la promoción del crecimiento y la igualdad social.

Sin embargo, en el siglo $\mathrm{xx}$ los principios que sustentaron la administración burocrática tradicional fueron modificándose en función del contexto socioeconómico y cultural (Merino, 2013). El derrumbamiento del Welfare State se produjo al terminar la Segunda Guerra Mundial, con el desarrollo y la generalización de la intervención del Estado. Mauricio Merino (2013) enfatiza que son tres razones las que se combinaron para modificar los viejos paradigmas del gobierno liberal: por un lado, la depresión previa a la Guerra había mostrado la necesidad de hacer intervenir al Estado en la producción y distribución de los ingresos, mientras que en la posguerra se colocó a la reconstrucción de Europa como una prioridad. Por otro lado, con el fin de la Guerra se inició la polarización del mundo por la disputa del liderazgo político y económico de la Unión Soviética y Estados Unidos. Esta disputa enfrentaba dos concepciones de la realidad social que, sin embargo, compartían la misma finalidad: la búsqueda de mejores condiciones para los individuos. El Estado social ocasionó el formidable crecimiento de las burocracias públicas y, además, ha provocado la creación de múltiples estructuras y ha incitado a nuevas formas de intervención y gestión (Mény \& Thoenig, 1992).

Entre tanto, la administración pública del bloque occidental se convirtió en el ente responsable de ejecutar los planes de desarrollo para lograr los fines de este Estado 
renovado no solamente basado en los principios del liberalismo, sino pretendiendo hacerlos más efectivos y ofreciendo el contenido material para alcanzarlos. ${ }^{4}$ Sin embargo, fue hasta el último cuarto de siglo cuando este modelo de grandes planes y objetivos fracasó. El pesimismo del Estado social se debe a dos fenómenos: por un lado, el descubrimiento por numerosos factores de la población de que la desigualdad que justificaba la creación y desarrollo del Estado social no había sido eliminado. Por otro lado, la confrontación con una crisis económica va a frenar, repentinamente, 30 años de crecimiento y desarrollo económico (Mény \& Thoenig, 1992).

El Estado en su papel de conductor y coordinador efectivo, a través de acciones en la mediación de problemas y promoción de las condiciones de bienestar y seguridad social para las clases desfavorecidas había entrado en crisis. En 1977 el Estado social había agotado sus expectativas y 12 años después, con la caída del Muro de Berlín como sentencia de muerte para el bloque socialista como líder político y económico, obligaron a imaginar nuevas posibilidades de acción para los gobiernos bajo los nuevos términos de economía: eficiencia y efectividad (Merino, 2013).

\section{Sobre la llamada "nueva gestión pública"}

Ante las condiciones de crisis y fracaso, la administración pública se volvió a la simplificación administrativa: la desregulación, desburocratización y desincorporación (Merino, 2013). En el contexto neoliberal se propone un nuevo movimiento en la administración pública con el nombre de nueva gestión pública. El académico Omar Guerrero dice, desde la visión del neoliberalismo, que se propone una brecha antinómica entre la administración y el nuevo manejo público; se trata de una dicotomía que separa a la tradicional weberiana y burocrática administración de un nuevo paradigma gerencial ágil, eficiente y moderno, basado en técnicas de la organización privada (Guerrero, 2000).

Propio de la cultura administrativa anglosajona, este enfoque se ha desarrollado en el terreno de la globalización, cuyo sumario aboga por principios liberales en los que los problemas del Gobierno pasan a un segundo término y la nueva gerencia pública asume el papel de promotor del mercado. ${ }^{5} \mathrm{El}$ resultado es un modelo estándar

\footnotetext{
4 En términos de Thomas H. Marshall (1949) fue en el Estado social en el que se reconocieron los derechos sociales, después del reconocimiento de los derechos políticos y civiles en la época de liberal.

5 El decálogo del Consenso de Washington fue etiquetado como punto crítico del neoliberalismo. Sus recomendaciones se basan en criterios de eficiencia, en el marco primordial de ordenar los mercados. Sus sugerencias pueden resumirse en: “a) aplicar una disciplina fiscal que incluya el buen funcionamiento de las finanzas públicas; b)
} 
de la administración pública para todos los países, que de tal modo asumen el mismo patrón de organización y funcionamiento (Guerrero, 1999; Rivera Lugo, 2007). Es Donald F. Kettl (2005) quien menciona los componentes de este movimiento que ya se estableció a nivel mundial: 1) mayor productividad social; 2) comportamientos vinculados al mercado; 3) orientación inclinada al servicio; 4) descentralización de las responsabilidades de programas a gobiernos subnacionales; 5) mecanismos para mejorar la claridad en la rendición de cuentas.

Aguilar Villanueva entiende por nueva gestión pública como "el cambio de las normas, las estructuras organizacionales y los patrones directivos y operativos del gobierno, que por sus propósitos, modos o resultados se orienta hacia formas posburocráticas de organización, dirección y operación con el fin de elevar la eficiencia, la calidad y la responsabilidad de la acción pública" (Aguilar Villanueva, 2006, p.146). Empero, a pesar de ya existir anteriormente el término de gestión pública (public managment) ${ }^{6}$, la nueva gestión pública (new public managment) significa simplementela implantación de la visión de los negocios privados dentro del Gobierno. De este momento, el texto anglosajón de mayor influencia sin duda fue La Reinvención del Gobierno, escrito por David Osborne y Ted Gaebler. Si bien fue en este texto que se popularizó la incorporación de las prácticas y el conocimiento empresarial en el Gobierno (Osborne \& Gaebler, 1992), solo representan una de las muchas vetas que se explorarían en esta vía.

Omar Guerrero establece cuatro características esenciales de la nueva gestión pública:

“1) El esfuerzo por disminuir o revertir el crecimiento del Gobierno; 2) el cambio hacia la privatización, con un renovado énfasis en la subsidiariedad de la provisión de servicios; 3) el desarrollo de la automatización en la producción y distribución de servicios, particularmente en tecnología informática; y, 4) el mayor desarrollo de una agenda internacional crecientemente enfocada en los temas generales del manejo público, el diseño de las políticas públicas, los estilos de decisión y la cooperación internacional" (Guerrero, 1999, p. 146).

\footnotetext{
establecer un orden de importancia en el gasto público, evitando el uso indiscriminado de subsidios y enfocándose más en la educación, la salud y la infraestructura; c) efectuar una reforma impositiva para ampliar la base fiscal de contribuyentes; d) liberar los mercados financieros para evitar los controles sobre las tasas de interés, evitando subsidios y créditos directos de parte del Gobierno; e) asegurar un tipo de cambio monetario competitivo para incrementar las exportaciones no tradicionales; f) aplicar una política de apertura comercial con todos los países; g) fomentar la inversión extranjera directa como fuente de capital y tecnología, y h) aplicar políticas de privatización, de desregulación y de derechos de propiedad".
}

6 Leonard White propone estudiar la administración pública fuera de las bases jurídicas, puesto que se trata de manejo de hombres y materiales para lograr el propósito del Estado, a decir: "El arte de la administración es la dirección, coordinación y control de muchas personas para realizar algún propósito u objetivo" (White, 1964, p.2). 
Este nuevo paradigma está basado en la idea de que los asuntos públicos deben estar manejados por gerentes profesionales, dotados de un control activo, visible y discrecional sobre los organismos. Por su parte, la organización empresarial en la administración pública está basada en estándares explícitos y medidores de calidad, así como en la definición de metas y objetivos; se basa en valores de competencia en el Estado, pues es la rivalidad entre el regulador de costos y de beneficios. Este paradigma se presenta no solo como alternativa a la burocracia weberiana, sino además como "medicina" para los males de la tradicional administración de la cosa pública; existe una colisión entre lo antiguo y lo decadente, y lo novedoso y vital (Guerrero, 1999): la administración pública tradicional elabora regulaciones y decisiones letárgicas, mientras que el nuevo manejo público se ostenta de innovación y entusiasmo por la actividad. Así entonces, el gobierno empresarial está dirigido para la satisfacción del ciudadano como consumidor.

Se debe aclarar que este enfoque no es vástago solamente de los fracasos de épocas anteriores, sino de resultados de confrontaciones ideológicas de la contemporaneidad, que en parte tienen que ver con las tendencias económicas y sociales que redefinen al Estado y a su organización frente a la globalización, a la economía del conocimiento, al desarrollo regional, a la revolución tecnológica, al resurgimiento de identidades locales y de riesgos ambientales. La nueva gestión pública reconoce que desde la década de los años ochenta, con las actividades de privatización de los gobiernos de Thatcher y Reagan, la actividad gubernamental ha tratado de simular algunas actividades del mundo comercial. Sin embargo, no es precisamente la intención del enfoque difuminar las barreras de lo público y lo privado. Precisamente es el sector público el que crea su propio modelo ya que la implementación de las acciones gubernamentales es más densa que la del sector privado, pues el Gobierno opera con instituciones, direcciones, departamentos y agencias. El sector particular, en contraste, es rápido y ágil por ser conformado por decisiones aisladas, dotadas de autonomía y con control limitado de la cima.

Rivera Lugo (2007) apunta, como consecuencia de lo anterior, a que el Gobierno debe estar orientado al nuevo manejo público y buscar una mayor adaptación e innovación institucionales, ya que limita la libertad de acción y restringe la iniciativa; es, en suma, la reforma de la actividad del Estado en su carácter de administración pública, depende de la prueba material de su desempeño, que consiste en la elaboración e implementación de políticas públicas (Rivera Lugo, 2007; Guerrero, 1999). Por ello, para Omar Guerrero la administración pública contemporánea se enfrenta al desafío de mejorar su implementabilidad; es decir, la capacidad de hacer accesible una idea en términos de acción a través de las relaciones dentro de la red de organizaciones, disposiciones y procedimientos. La implementabilidad es un proceso que sustenta al Gobierno mediante el que rinde dividendos en términos de legitimidad, consenso y rentabilidad (Guerrero, 1999). Un gobierno con poca eficacia en la implementabilidad 
puede ser manifiesto en los deficitarios fiscales, el deterioro de los servicios públicos y la lentitud del despacho de los negocios administrativos.

No es precisamente la administración pública la que ha menguado en cada etapa de la evolución que apretadamente se ha descrito. Por el contrario, ha sido la continuidad a través de sus organizaciones.

$\mathrm{Y}$ es precisamente en esta nueva realidad donde el monolito gubernamental se fragmenta: las dependencias gubernamentales se bifurcan, se contraponen y se disputan espacios y recursos -escasos por demás, en concordancia con el déficit del gasto público-. Es en este proceso de fragmentación donde por las rendijas se filtran intervenciones de las organizaciones de la sociedad civil. Es en esta época en la que recae la explicación de las fuerzas centrífugas del proceso de gobernar, se vuelve en un proceso iterativo entre las agencias gubernamentales y civiles. Además, la nueva realidad condicionada por un escenario que convive con la múltiple interacción de actores, de variables exógenas que condicionan el actuar de las organizaciones gubernamentales y las obligan a desarrollar procesos adaptativos. Es aquí donde la capacidad de lo legal-racional se traslapa con el entendimiento del comportamiento. A partir de este momento la administración pública tradicional deja de arrojar luz para entender el acontecer del proceso de gobernar. Es en ese sentido, la variedad de enfoques de la administración pública desde la óptica de distintas disciplinas -en palabras de Mauricio Merino (2013)- la multiplicación de los objetos de estudio que han abordado la disciplina de la administración pública pueden llegar a explicar el éxito de las políticas públicas.

La realidad de la administración pública -como se trató de explayar en el recorrido de antecedentes- por su tradición, su organización burocrático-legal, sus dependencias políticas o la falta de indicadores fiables de gestión comparables a los del sector privado para medir los resultados, hacen difícil la aplicación de técnicas procedentes del management a la administración pública. Por esto, Subirats (1989) observa que es pertinente introducir el enfoque del análisis de las políticas públicas, al combinar la mentalidad de mejora de la gestión administrativa con plena conciencia de las características propias del sector público.

\section{Para comprender "políticas públicas"}

Siendo el de las políticas públicas un campo sobre el que se ha escrito y reescrito desde distintas perspectivas, la construcción de un cuerpo de conocimiento consistente no es tarea sencilla. De manera intuitiva, se le asocia con la estructura, las jerarquías y la burocracia, pero su comprensión detallada requiere de algo más que sentido común. 
La autoridad pública solo existe en sus acciones. La administración pública, mediante sus funcionarios y servidores públicos, actúa. Por su parte, los funcionarios y servidores públicos intervienen por medio de acciones en la sociedad que los elige (por lo menos en las sociedades democráticas), pues se ven en la imperiosa necesidad de decidir cómo actuar frente a la realidad social. La intención de actuar tiene raíz por diferentes motivos: los planes de desarrollo del Gobierno o la satisfacción de las demandas de los ciudadanos por acontecimientos específicos urgentes. Sin embargo, la acción gubernamental, a su modo, tiene efectos directos e indirectos en la sociedad. Lo anterior es precisamente el objeto de estudio de las ciencias de las políticas públicas (Policy Sciences), la acción de las autoridades públicas en el seno de la sociedad (Mény \& Thoenig, 1992).

En origen, las políticas públicas pueden comprenderse, en parte, por la intención de este campo del conocimiento; de manera específica en la serie de documentos hoy en resguardo de la Universidad de Yale ${ }^{7}$ de Harold D. Lasswell (2003). Lo que se busca con las políticas públicas es:

a. Integrar la moral (entendida como la dignidad de la persona humana), la ciencia y la política.

b. Perfeccionar la inteligencia y la racionalidad de las decisiones de lo gubernamental. Esto a través de:

- La claridad en las metas, la oportunidad y la moralidad de lo que se propone.

- La claridad en las alternativas de acción.

- La identificación de la información pertinente sobre riesgos y relaciones causales alrededor de la problemática identificada.

- La creatividad sobre los medios y alternativas para conseguir resultados.

- La operación del todo, considerando el bien común.

Así, la política pública fue evolucionando como concepto hasta convertirse en un instrumento particular de toda la actividad del Estado, "todo lo que los Gobiernos deciden hacer o no hacer” (traducción libre de Dye, 2005).

Por otro lado, de acuerdo con Velázquez Gavilanes (2009), por ser bastante general, no solo deja por fuera a elementos como la implementación y evaluación, sino además permite considerar como política pública decisiones o intervenciones

$7 \quad$ En la revista Policy Sciences, número 36 del 2003, páginas 71 a la 98, se reproducen documentos semanales de Harold D. Lasswell (datan de 1943 pero por la fuente se identifican con el año 2003). 
que no lo son. Para corresponder a una definición adecuada, comenta Mauricio Merino:

"Han de ser decisiones tomadas por los órganos ejecutivos o representativos del Estado -y no por los particulares- con el propósito explícito de modificar el statu quo en un sentido determinado, mediante el uso de los recursos normativos, presupuestarios y humanos con los que cuenta el sector público al menos parcialmente o como punto de partida- y en un horizonte temporal razonablemente definido" (Merino, 2013, p. 17).

Esta definición agrega un elemento importante en el campo de las políticas públicas: concebir la política pública como un proceso deliberativo. Es decir, el diseño de la política pública no consiste en el enunciado de una voluntad política para resolver problemas públicos; además, exige un proceso racional, informado y comprometido de selección y definición de problemas, a partir de los medios efectivamente disponibles para solucionarlos. También supone, desde lo que se define como problema público, el planteamiento de resultados que se desea obtener y el proceso a través del cual serán conseguidos.

Por lo tanto, la política pública es entendida como un proceso causal de decisiones, acciones u omisiones gubernamentales, en medida de sus facultades y con la posibilidad de participación de los particulares para corregir, modificar o prevenir una situación considerada problemática por medio del uso de recursos jurídicos, presupuestarios y humanos. Además, se le atribuyen de manera general cinco características: un contenido, un programa, una orientación normativa, un factor de coerción y una competencia social (Mény \& Thoenig, 1992). Sin embargo, se hace hincapié en la orientación normativa y el programa. La orientación normativa se refiere a la carga valorativa de los actos del Estado: es la expresión de las finalidades y de preferencias del decisor. Las acciones traducen orientaciones brindadas y delimitadas por la axiología de las normas en un contexto espaciotemporal: lo que debe suceder.

En los primeros estudios de la ciencia de la administración pública se supedita la voz policy (políticas públicas) como objeto de estudio dentro de su disciplina. En sus primeros estudios, Frank Goodnow utilizaba el término de política como guía o la influencia sobre la policy gubernamental y de la administración como la ejecución de esta: con ello, el autor abre un tema para discusión en la materia al separar la política de la administración (Guerrero, 2000). Años más adelante, ante la exigencia de la rigurosidad conceptual, en su clásica obra, Leonard White propone la política pública como categoría central en la definición de la administración 
públicas; mientras que deja claro que el éxito o fracaso de la administración pública depende en el carácter de la política pública y como se formula en la legislación (Rivera Lugo, 2007).

Con una perspectiva opuesta a la de Goodnow, Dimock (citado por Guerrero, 2000) propone que los servidores públicos participaban tanto en la elaboración como en la ejecución de las políticas públicas. Lo interesante de su propuesta fue que el término de políticas públicas incluye toda la actividad del sistema político. Así mismo, es la mediación entre la política y la administración pública: por política es todo lo que hace el Gobierno para determinar las políticas públicas, y por administración pública está relacionado con el qué y con el cómo del Gobierno (Guerrero, 2000).

Sin embargo, estas posturas dentro de la ciencia de la administración pública fueron rechazadas por facilitar la evaporación de consolidar su singularidad como disciplina, por aceptar su naturaleza política. Esto facilitó el desarrollo del pensamiento de la ciencia política sin beneficiar el estudio de la administración pública.

Para quienes busquen un punto en la historia, la Segunda Guerra Mundial es un ejemplo de cuando un enfoque adquiere precisión académica. En este contexto fue la preocupación por la eficacia de los Gobiernos derivado de la complejidad política, económica y social en la que habría de desenvolverse (Merino, 2013).

La orientación a las políticas (policy orientation) puede constituir un llamamiento para mejorar la racionalidad e inteligencia al proceso de toma decisiones. Con el nacimiento de este enfoque, agrega Mauricio Merino: "se fue dejando atrás el intento de construir una teoría general de la administración pública para comenzar a estudiar los medios intelectuales, normativos y técnicos más adecuados para definir, diseñar y organizar la intervención del Estado, caso por caso" (2013, p. 36).

En la actualidad, la dicotomía sigue vigente: por un lado, como corriente de la ciencia de la administración pública, el estudio de las políticas públicas presenta sus propias características y genera una metodología particular (Lasswell, 2003; Ferrero, 2009; Rivera Lugo, 2007). Omar Guerrero arguye que además de ser la ciencia de la administración pública uno de los terrenos primigenios de este enfoque, sigue siendo una disciplina fértil para la creatividad y su desarrollo: "La administración pública, en su más amplio sentido, está involucrada con la hechura de la policy por cuanto a ella corresponde su ejecución" (Guerrero, 2014, p. 13). En otras palabras, colaborar de manera significativa con la ciencia de la administración pública ayuda a enriquecer su presencia y actividad en un ámbito de conocimiento: la implementación de las políticas públicas.

$8 \quad$ "La administración pública consiste en todas las operaciones que tienen por objeto la realización o la observancia forzosa de la política del Estado" (White, 1964, p. 1). 
Por otra parte, el enfoque de las políticas públicas como marco de análisis de la acción gubernamental rompe con los supuestos básicos de la administración pública por tres razones:

c. Antepuso el análisis propio de la política pública sobre el análisis que se deriva de la dependencia gubernamental.

d. El proceso decisorio sobreviene ante la norma jurídica como base de sus estudios.

e. Se opone al acotado campo de la administración pública, la amplia gama de vínculos e intersecciones entre los ámbitos político y administrativo.

En ese sentido, Mauricio Merino (2013) apunta que este nuevo enfoque no representa una continuación de la disciplina de la administración pública ni es consecuencia lógica de su evolución, sino una alternativa al objeto de estudio de la ciencia administrativa: "Si la administración pública quería ser una disciplina capaz de abarcar a la totalidad de las estructuras creadas para resolver necesidades sociales en nombre del conjunto, las políticas públicas parten de la singularización de los problemas y las respuestas" (Merino, 2013, p. 30). Por ello, el Gobierno deja de ser un conjunto de autoridades públicas unidas por un proyecto único, por su incapacidad de consenso que la actual sociedad democrática le pueda dar; para evolucionar a ser un Gobierno productor de decisiones y de cursos a seguir. Por su parte, el profesor Aguilar Villanueva agrega:

Gobernar en contextos políticos plurales y autónomos, de alta intensidad ciudadana y con graves problemas sociales irresueltos, parece exigir dos requisitos fundamentales: gobernar por políticas y gobernar con sentido público. Las estrategias de gobierno homogéneas y globales, así como los estilos de gobierno secretos, excluyentes y clientelares, están previsiblemente condenadas en el futuro inmediato a la ineficacia administrativa, al castigo electoral y a la hostilidad política” (Aguilar Villanueva, 2000, p. 30).

\section{Apuntes finales, manera de conclusión}

Lo comprendido en estas páginas abarca siglos. Es claro que, en un esfuerzo sintético, ideas y autores fueron injustamente obviados. Lo pretendido, sin embargo, fue presentar al lector un recorrido temporal y conceptual del Estado, como figura o idea 
amplia, y su especialización hacia el momento en que "políticas públicas" se presenta como lo más contemporáneo para su conocimiento.

La tradición latinoamericana, construida con énfasis en lo normativo y la planeación para lo gubernamental, se enfrenta contra el paradigma que contienen a las políticas públicas. El tránsito para su adopción requiere de un estudio racional, así como la valoración de voces locales, conocedoras de la experiencia y el contexto. Por su eminente vocación práctica, volcarnos hacia las políticas públicas demanda más que un aprendizaje teórico: la reflexión, desde nuestros contextos, del lugar que podría ocupar en la academia, la arena política, los corredores y pasillos gubernamentales.

Al día de hoy, como una propuesta conceptual más terminada, aquella que identifica a la política pública con una "intervención deliberada del Estado para corregir o modificar una situación social o económica que ha sido reconocida como problema público" (Merino, 2013, p. 17). Las aproximaciones conceptuales parecen mucho más claros pero todavía hay mucho por comprender.

Por nuestra tradición histórica y la manera en la que se han integrado y construido nuestras comunidades y nuestros Gobiernos, los asuntos importantes quieren abordarse únicamente desde el punto de vista normativo; la especialización, cuando se trata de lo público, se ha dado, entonces, en la área del derecho. Al día de hoy, lo complejo de la comunidad y sus demandas, así como una transformación en la concepción de lo gubernamental y la interrelación global, obliga a un abordaje plurimulti-transdisciplinario donde (no hay sorpresas) las discrepancias pudieran hacerse presentes en lo cotideano.

Producto de la Edad Media, la idea del Estado facilitó la construcción de espacios de convivencia más o menos pacífica; en términos generales, el establecimiento de un pacto y la claridad de los límites del dominio de quienes ejercían el poder, promovió el desarrollo de una concepción mucho más regional y la preocupación por la mejora del trabajo de quienes, hasta entonces, ejercían alguna función en lo público. Para la segunda mitad del siglo pasado, aquella solución resultó insuficiente: la atención se centró, entonces, en cómo un Gobierno podía integrar elementos diferentes (humanos y financieros) en su toma de decisión. Eso de las políticas públicas es el espacio del conocimiento que agrupa, con el riesgo de las discrepancias y sufriendo lo que toda propuesta nueva, una parte importante de lo que se ha intentado.

El camino hacia un Estado de políticas públicas no es sencillo de trazar. Si la metáfora se permite, va construyéndose y resolviéndose paso a paso. La dirección tomada es la que la realidad ha impuesto; seguimos en aquella pretención nada modesta de Harold D. Lasswell (2003) de querer incrementar la racionalidad del quehacer público. 
Un tránsito hacia las políticas públicas requiere un enfoque más cercano a la efectividad en la toma de decisiones y no tanto a la obsesión de encontrar, sea en la academia o en la política, una definición oponible a todos.

\section{Referencias bibliográficas}

Aguilar Villanueva, L. F. (2000). Estudio introductorio. En L. F. Aguilar Villanueva, La implementación de las políticas (págs. 15-92). México: Miguel Ángel Porrúa.

Aguilar Villanueva, L. F. (2006). Gobernanza y gestión pública. México: Fondo de Cultura Económica.

Dye, T. R. (2005). Understanding public policy. New Jersey: Prentice Hall.

Ferraro, A. (2009). Reinventando el Estado. Por una administración pública democrática y profesional en Iberoamerica. Madrid: Instituto Nacional de Administración Pública.

Fraga, G. (2009). Derecho administrativo. México: Porrúa.

Guerrero, O. (1992). El Estado en la Era de la Modernización. México: Plaza y Valdés.

Guerrero, O. (1999). Del Estado gerencial al Estado Cívico. México: UNAM.

Guerrero, O. (2000). Management público, un concepto elusivo. Cuatro variaciones. Revista de Administración Pública, 191-224.

Guerrero, O. (2000). Teoría administrativa del Estado. México: Oxford University Press.

Heller, H. (2010). Teoría del Estado. México: Fondo de Cultura Económica.

Kettl, D. (2005). The global public Management Revolution. Washington: Brookings Institution Press.

Lasswell, H. D. (2003). “On the policy sciences in 1943". Policy Sciences, pp 71-98.

Marshall, T. H. (1949). Ciudadanía y clase social. En Corporativo, Cátedras UBA Argentina (pág. electrónico). Buenos Aires: UBA.

Maquiavelo, N. (1975). El Príncipe. México: Porrúa.

Mény, I. y Thoenig, J.-C. (1992). Las políticas públicas. Madrid: Ariel. 
Merino, M. (2013). Políticas públicas. Ensayo sobre la intervención del Estado en la solución de problemas públicos. México: CIDE.

Osborne, D., y Gaebler, T. (1992). La reinvención del Gobierno. La influencia del espíritu empresarial en el sector público. Madrid: Paidós.

Parsons, W. (2007). Políticas Públicas. Buenos Aires: FLACSO, Miño y Dávila.

Porrúa Pérez, F. (1976). Teoría del Estado. México: Porrúa.

Pokrovski, V. S. (1966). Historia de las ideas políticas. México: Grijalbo.

Quiroga Lanvié, H. (1987). Derecho constitucional. Buenos Aires: Ediciones Depalma.

Rivera Lugo, F. R. (2007). Gerencia cataláctica: anatomía de la Nueva Gerencia Pública. México: Porrúa.

Sartori, G. (1992). Elementos de teoría política. Madrid: Alianza Editorial.

Subirats, J. (1989). Análisis de políticas públicas y eficacia de la administración. Madrid: INAP.

Theodoulou, S. Z. (1995). The nature of public policy. En S. Theodoulou, \& M. Cahn, Public policy. The essential readings (págs. 1-9). Nueva Jersey: Prentice Hall.

Velázquez Gavilanes, R. (2009). Hacia una nueva definición del concepto "política pública”. Desafíos, pp. 149-187.

Weber, M. (2002). Economía y sociedad. México: Fondo de Cultura Económica.

Wright Mills, C. (1964). Poder, política y pueblo. México: Fondo de Cultura Económica.

White, L. (1964). Introducción al estudio de la administración pública. México: Compañía General de Ediciones.

Zarka, Y. C. (2001). Figuras del poder. Estudios de filosofía política de Maquiavelo a Foucault. Madrid: Biblioteca Nueva. 